Print ISSN: 2234-3040 / Online ISSN 2234-3059

doi:10.13106/eajbm.2018.vol8.no2.15

\title{
Study on Tourism Carbon Emissions and Distribution Efficiency of Tourism Economics
}

\author{
Xiaoyu Cheng*, Keshen Jiang** \\ Received: December 4, 2017. Revised: December 26, 2017. Accepted: April 15, 2018.
}

\begin{abstract}
Purpose - It is important to figure out the relationship between tourism carbon emissions and tourism economics for a healthy tourism development.

Research design, data, and methodology - Data of this study are collected from 27 provinces (cities) of China. Tourist consumption stripping coefficient is used to calculate tourism carbon emissions. SBM-Undesirable model is used to measure the efficiency of tourism economics under the constraint of tourism carbon emissions.

Results - The results show that: during the year of 2005-2015, there are obvious differences in totals and intensities of tourism carbon emissions among 27 provinces and cities which can be divided into three areas. There is a high possibility of underestimating the actual efficiency of tourism economics by leaving tourism carbon emissions out of account, and a high inefficiency caused by tourism carbon emissions will lead a low efficiency of tourism economics.

Conclusions - The development of tourism should give consideration to both economic and environmental benefits, and reduce the inefficiency caused by tourism carbon emissions to improve efficiency of tourism economics by improving the level of technical efficiency and promoting technological progress.
\end{abstract}

Keywords: Tourism Carbon Emissions, Efficiency of Tourism Economics, Tourist Consumption Stripping Coefficient, SBM-Undesirable Model.

JEL Classifications: L83, Q56, R15.

\section{Introduction and Literature Review}

The tourism of China is a rapidly growing industry with remarkable achievements, however, the rapid development of the tourism industry and the continuous carbon emissions are in parallel. A study of UNWTO found that tourism carbon emissions have accounted for $14 \%$ of global warming, if we stay unmoved, then the carbon emissions related to tourism will increase by $2.5 \%$ annually before 2035. As a response, China decide to reduce carbon emissions by $60 \%-65 \%$ during the year of $2005-2030$ in the

* First Author \& Corresponding Author, College of Economics and Management, Nanjing University of Aeronautics and Astronautics, China. Tel: +86-156-5188-5207, E-mail: nuaacxy@163.com

** Second Author, College of Economics and Management, Nanjing University of Aeronautics and Astronautics, China.

Tel: +86-136-5517-5909, E-mail: jiangksh@126.com
"Paris agreement" which will come into force in 2016.

It is important to learn more about carbon emissions related to tourism to fix the problem we faced now. In China, the direct monitoring of tourism carbon emissions can't be realized at present for technology problems and so on. For literature review, the measurements of tourism carbon emissions can be basically divided into three types: top-down and bottom-up, including the input and output method (Becken \& Patterson, 2006), carbon footprint (Camelia, Razvan, \& Breda, 2012) and ecological footprint method (Munday, Turner, \& Jones, 2013). Tao, Huang, Wu, $\mathrm{Yu}$ and Wang (2014) systematically measured the total carbon emissions of tourism and made further effort to decompose it. Li (2015) proposed special measurement way for carbon emissions of scenic spots. Sun, Zhang, Tang, $\mathrm{Hu}$, and Chen (2016) evaluated the research progress on carbon emissions of tourism traffic. Performance appraisal has a significant influence on tourism carbon emissions, the 
research on tourism industry efficiency abroad began in 1980s, which involved various tourism enterprises, such as travel agencies, hotels, tourist traffic and other (Barros, 2006). For China, the related researches started in early twenty-first Century vary between inter-city (Wang, Huang, Tao, \& Fang, 2013), inter-provincial (Fang, Huang, Yu, \& Tu, 2013), inter-area (Gong, Zhang, \& Tang, 2016), nation (Zhao, 2016). However, all the researches mentioned above didn't take carbon emissions into consideration, in other words, carbon emissions always be ignored for the inertia thinking of 'smoke-free' on tourism. Han and Wu (2016) estimated the tourism efficiency of five regions during the year of 2009-2011 by taking tourism carbon emissions as undesirable output, but the research scope is very limited. Zha (2016) measured the efficiency of low carbon tourism of 17 cities in Hubei Province based on input-output table, but there was also an annual limit.

It is important to realize the quantitative analysis of low carbon tourism by measuring tourism carbon emissions to improve the study on tourism efficiency under the constraint of carbon emissions. Considering the availability of data, this paper choose 27 provinces (without Hebei, Henan, Guangxi, Tibet, Hongkong, Macao, Taiwan) as objects to measure tourism carbon emissions with the help of tourism consumption stripping coefficient. SBM-Undesirable model will be used to measure and compare the tourism efficiency between constraint and non-constraint of carbon emissions, and the model will also be used to decompose the inefficiency of tourism.

\section{Methodology}

\subsection{Estimation Method of Tourism Carbon Emission}

Carbon emissions in this paper refer to emissions of $\mathrm{CO}_{2}$, which mainly originate from energy consumption, however, tourism is not included in the statistics, and tourist consumption stripping coefficient is introduced to solve the problem, namely "the proportion of added value of tourist consumption in service industry"(Li \& Li, 1999). The way of estimation is to strip tourism energy consumption from the energy consumption of industries related to tourism by tourist consumption stripping coefficient, and then convert it into tourism carbon emissions through the energy conversion coefficient. Referring to the 'National Tourism and related industries statistical classification 2015 '(GB/T4754-2011) and the 'Energy Statistics Yearbook', industries related to tourism are decided as Transportation, Warehousing and Postal industry, Wholesale and Retail industry, Hotels and Catering Services industry. The formula of tourist consumption stripping coefficient is:

$$
A_{i}=T_{i} / N_{1}
$$

$A_{i}$ refers to tourist consumption stripping coefficient of $\mathrm{i}$ industry, $T_{i}$ refers to the added value of tourism from $\mathrm{i}$ industry, it is the product of value-added rate and tourism revenues of $\mathrm{i}$ industry, value-added rate of $\mathrm{i}$ industry is the ratio of added value in the total output value of $\mathrm{i}$ industry, tourism revenue of $\mathrm{i}$ industry is the product of tourism income and the ratio of tourist consumption related to $i$ industry, $N_{i}$ refers to added value of i industry.

The formula of tourism carbon emissions is:

$$
c=\Sigma \Sigma_{i=1}^{n}\left(E_{i j} A_{i} r_{j} \beta\right) \quad(n=1,2 . \cdots)
$$

C represents the total carbon emissions of tourism, $E_{i j}$ says energy $\mathrm{J}$ which is consumed by $\mathrm{i}$ industry, Ai says the tourist consumption stripping coefficient of $i$ industry, $r$ says reference coefficient of standard coal for energy conversion of energy $\mathrm{j}, \beta$ say emissions of $\mathrm{CO}_{2}$ per unit of standard coal, $\beta=2.45$ (Chen \& Zhu, 2009).

\subsection{Estimation and Decomposition Method of Tourism Efficiency}

Data envelopment analysis (DEA) and stochastic frontier analysis (SFA) are most frequently used to determine the level of efficiency by evaluating the relative effectiveness of decision making units (DMU), SFA belongs to parametric method involving the parameter equation estimation, while DEA belongs to non-parametric method, in this paper DEA is selected to calculate the efficiency of tourism industry.

DEA is rooted in CCR model by Charnes, Cooper and Rhodes (1978), after that, a lot of extended researches were proposed, including directional distance function of SBM (Slacks-Based Measure) by Tone, which was set to solve problems of traditional DEA model with angle and radial who ignores the slackness during input and output, it can solve the problem with bad output. The formula is shown as below:

$$
\begin{gathered}
\rho^{*}=\min \frac{1-\frac{1}{m} \sum_{i=1}^{m} S_{i}^{-} / x_{i 0}}{1+\frac{1}{s_{1}+s_{2}}\left(\sum_{r=1}^{s_{1}} S_{r}^{g} / y_{r 0}^{g}+\sum_{r=1}^{s_{2}} S_{r}^{b} / y_{r 0}^{b}\right)} \\
\text { s.t. } \quad x_{0}=x \lambda+S^{-} \\
y_{0}^{g}=Y^{g} \lambda+S^{g} \\
y_{0}^{b}=Y^{b} \lambda+S^{b} \\
\lambda \geq 0, S^{-} \geq 0, S^{g} \geq 0, S^{b} \geq 0
\end{gathered}
$$

In (3), $\left(x_{0}, y_{0}^{g}, y_{0}^{b}\right)$ says the input, output, bad output vector of SBM-Undesirable model, $\mathrm{m}, s_{1}, s_{2}$ respond to the number of assumptions of input, output, bad output respectively, $\left(S^{1}, S^{g}, S^{b}\right)$ is a slack variable vector which 
can be understood as the redundant input, insufficient output, and redundant bad output of DMUs, $\lambda$ says the adjustment matrix, $\rho^{*}$ says the efficiency value of DMU $\left(x_{0}, y_{0}^{g}, y_{0}^{b}\right)$ and it ranges $0 \leq \rho^{*} \leq 1$. According to (3), the inefficiency value can be decomposed as (4), which represent the ratio of redundancy of bad output and actual bad output.

$$
I E_{b}=\frac{1}{s_{2}} \Sigma_{r=1}^{s_{2}} S_{r}^{b} / y_{r 0}^{b}
$$

\subsection{Data Sources}

The estimation of tourism carbon emissions is based on "China Statistical Yearbook", "China Tourism Statistical Yearbook", "Tourism Sampling Survey", "China Energy Statistical Yearbook" during year of 2006-2016, and "General Principles for Calculation of Total Production Energy Consumption" of GB/T 2589-2008.

The measurement tourism efficiency involves the indicator selection of input and output. From the perspective of production, for input indicators, capital, labor and land can be respectively represented as original value of fixed assets of tourism enterprises, tourism employees, tourism resource endowment, where A-class tourist attractions will be weighted. Tourism gross income is selected to represent desirable output, and tourism carbon emissions is selected to represent bad output, tourism energy consumption is a corresponding input indicator to tourism carbon emissions. Indicators originate from "China Tourism Statistical Yearbook" during the year of 2006-2016.

\section{Results}

\subsection{Estimation of Tourism Carbon Emissions}

The calculation of tourism carbon emissions is an important part of quantitative analysis of low carbon tourism, and is also an important prerequisite for further study on tourism efficiency. In this paper, 27 provinces and cities can be divided into three regions as the East, the Central and the West. The calculation is divided into two steps, the calculation of total and the calculation of intensity.

\subsubsection{Total of tourism carbon emissions}

There is a huge difference of total tourism carbon emissions among provinces and cities. The average emissions of Guangdong and Sichuan are larger than 20 million tons, while the average emissions of Ningxia, Qinghai and Hainan are lower than 2 million tons, the average carbon emissions of other provinces and cities are between 200-2000 million tons. <Figure $1>$ is a tendency chart of tourism carbon emissions among 27 provinces and cities, in which two bar graphs and one line chart are listed, it is important to note that two bar graphs respectively represent total tourism carbon emissions in 2005 and 2015 and the line chart represents average growth rate of carbon emissions during the year of 2005-2015, the provinces and cities are shown in descending order according to the total tourism carbon emissions. From the perspective of gross tourism carbon emissions, the difference among provinces and cities is large. Guangdong ranked the first in 2005 with tourism carbon emissions reaching 19 million 700 thousand tons, while Ningxia ranked bottom with 290 thousand tons only. In 2015, Sichuan reached the largest carbon emissions of 62 million 980 thousand tons, and Ningxia stayed its rank of 1 million 40 thousand tons. From the perspective of average growth rate of tourism carbon emissions, Shanghai is the only city with a negative growth of $-0.34 \%$, and also at a low level of total tourism carbon emissions. The average growth rate of tourism carbon emissions in other provinces and cities tend to be positive, the rate of Anhui, Gansu, Jiangxi, Sichuan is greater than $30 \%$, and the rate of Zhejiang, Beijing, Liaoning, Guangdong is lower than $10 \%$.

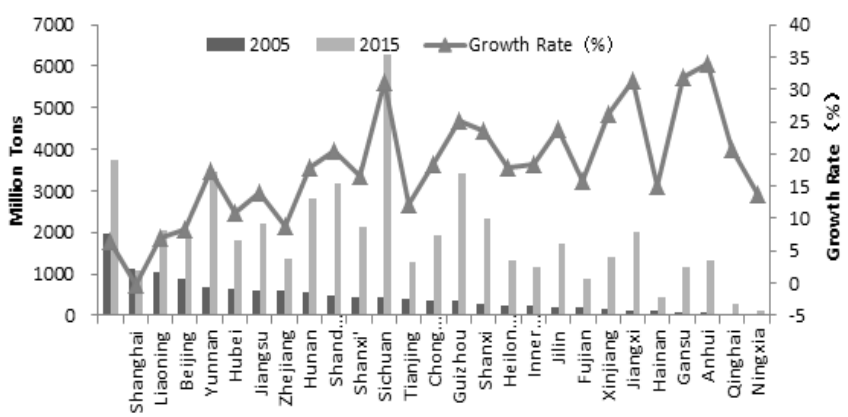

<Figure 1> Tendency Chart of Tourism Carbon Emissions among 27 Provinces and Cities

From the regional perspective, the average value of tourism carbon emissions during the year of 2005-2015 amounts to 119 million 890 thousand tons in the east, 55 million 60 thousand tons in the middle and 90 million 920 thousand tons in the west, where the east area ranked the first and followed by the west area and the middle area. The corresponding average growth rates during the year of $2005-2015$ in the three areas are respectively presented as $9.38 \% 20.09 \%, 22.57 \%$, the west is the fastest area while the east is the slowest area, and the middle area is close to the west. <Figure $2>$ is a tendency chart of tourism carbon emissions of three areas during the year of 2005-2015. It can be seen that the overall trend of total tourism carbon emissions of the three areas are increasing with the east area, the west area and the middle area ranking in descending order, but the west area surpassed the east area in 2015. The change of tourism carbon 
emissions of the three areas will be easier analyzed by separating the period of 2005-2015 into three parts: Firstly, during the period of $2005-2008$, the east area changes greatly and showed a down up down trend, both the middle area and the west area show a slow trend of growth; secondly, all of the three areas have a rapid growth during the period of 2008-2012, and the growth rates of middle area and west area are higher than the east area; finally, during the period of 2012-2015, the east area shows a down up down trend, while both middle area and west area show a rapid growth, the growth rate of the west area is significantly higher than the east area but slightly higher than the middle area.

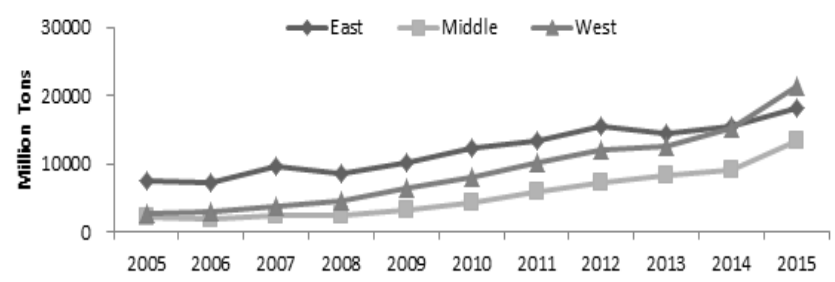

<Figure 2> Tendency Chart of Tourism Carbon Emissions of Three Areas (2005-2015)

\subsubsection{Intensity of tourism carbon emissions}

Tourism carbon intensity can be defined as the carbon emissions accompanied by the unit growth of added value of tourism industry, it is an important index to measure the relationship between tourism economics and carbon emissions, and to evaluate the development of low-carbon tourism. The formula is the ratio of tourism carbon emissions to added value of tourism industry.

There are four parts in figures 3 respectively marked as i, ii, iii, iv, which indicate the distribution of tourism carbon intensity among 27 provinces and cities in 2005, 2010, 2015 and 2005-2015 respectively (the blanks represent unincorporated areas, and the South China Sea is not shown in the map). <Figure 4> indicates the distribution of tourism carbon intensity among 27 provinces and cities during the year of 2005-2015, the range of tourism carbon intensity is $0-4$, it is obvious that there is a significant difference in the value of tourism carbon intensity among provinces and cities where Yunnan and Gansu are larger than 3, but Jiangsu, Zhejiang, Shanghai and Fujian are less than 1. The comparison between <Figure 1> and <Figure 2> show that, during the year of 2005-2010, there is an obvious decline of tourism carbon intensity in Ningxia, Qinghai, Yunnan, Guizhou, Hubei, Liaoning, Shaanxi, Xinjiang, Hainan, Heilongjiang, Hunan, Tianjin, Zhejiang, and there is an obvious increase of tourism carbon intensity in Sichuan and Shanxi. The comparison between <Figure 2> and <Figure 3> show that, during the year of $2010-2015$, there is an obvious decline of tourism carbon intensity in Qinghai, Sichuan, Shaanxi, Inner Mongolia, Guangdong, Shanghai and Fujian, and there is an obvious increase of $\mathrm{TCl}$ in Anhui, Heilongjiang, Hunan and Xinjiang. The comparison of <Figure 1>, <Figure 2> and <Figure 3> show that, during the year of 2005-2015, Qinghai and Ningxia maintain an obvious decline in tourism carbon intensity; the tourism carbon intensity of Heilongjiang, Hunan, Xinjiang tend to rise after first drop, where Hunan present a decline trend but Heilongjiang and Ningxia present a rising trend in general; Sichuan tend to decrease after first rise and present a rising trend in general. The overall trend of tourism carbon intensity of 27 provinces and cities tend to decline.

In general, the provinces and cities with low tourism carbon intensity are concentrated in the east and the higher are concentrated in the west. There is an obvious difference in tourism carbon intensity among areas, it can be seen that the east, the middle, the west are in ascending order according to the value of tourism carbon intensity, and the average value of tourism carbon intensity during the year of $2005-2015$ of the three areas in turn is $1.26,1.67,2.66$ respectively, the distribution level of tourism carbon intensity among provinces and cities is consistent with the overall level of areas.

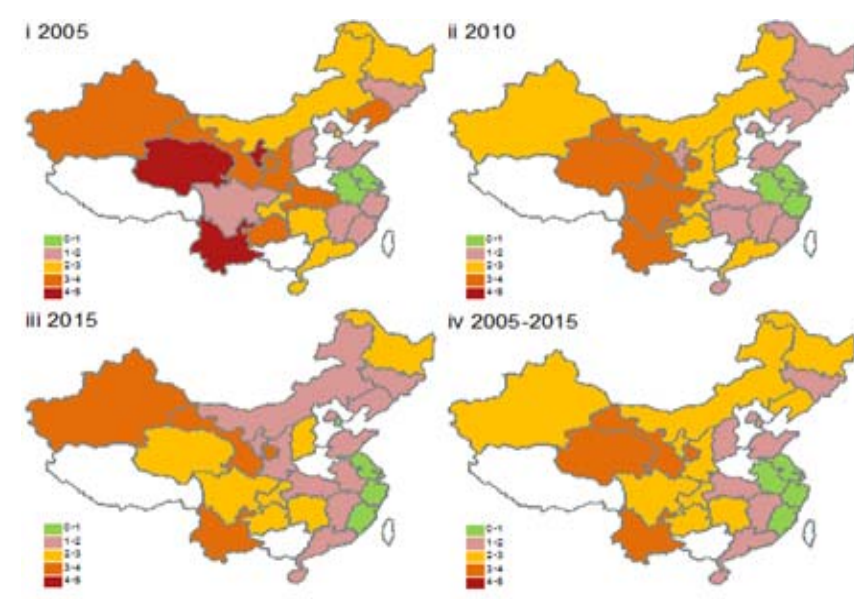

<Figure 3> Distributions of tourism carbon intensity among provinces and cities

\subsection{Relationship between Tourism Carbon Emissions and Tourism Economics}

Performance appraisal is an important way to explore the relationship between tourism carbon emissions and efficiency of tourism economics. The efficiency of tourism economics will be measured by MATLAB R2016a under the guidance of SBM-Undesirable model.

The result in <Table $1>$ based on SBM-Undesirable model is static, says the different production frontiers resulted from 
different technologies in different years, in that case, the efficiency of tourism economics can only be compared in the cross-section. The values of efficiency in <Table $1>$ during the year of 2005-2015 in 27 provinces and cities are arranged by areas of the east, the middle and the west. The efficiency of tourism economics in Tianjin and Shanghai are valid at any technical level during the year of 2005-2015, and the other provinces and cities are invalid to different degrees. There are some obvious differences of efficiency among provinces and cities, ranging between 0.7-1. For efficiency of tourism economics, some provinces and cities are in the interval of $0.9-1$, such as Shanghai (11), Tianjin (11), Anhui (11), Jiangsu (9), Zhejiang (8), Fujian (8), Guizhou (5), Beijing (4), Jiangxi (3), Hubei (3), Guangdong (2), Jilin (1), Yunnan (1), Shandong (1), Inner Mongolia (1), Liaoning (1). And some are in the interval of 0.7-0.8, such as Gansu (11), Qinghai (11), Ningxia (11), Xinjiang (11), Yunnan (10), Chongqing (9), Shanxi' (9), Heilongjiang (9), Sichuan (9), Inner Mongolia (8), Liaoning (8), Jilin (8), Shanxi (7), Hunan (7), Hainan (7), Guizhou (4),
Hubei (5), Guangdong (5), Beijing (3), Shandong (2), Jiangxi (2). The figures in brackets indicate the frequencies of tourism efficiency in 27 provinces during the year of 2005-2015 that appeared in the assumed range. During the year of 2005-2015, in conclusion, provinces and cities of higher efficiency of tourism economics are concentrated in the east, while the lower are concentrated in the west.

The result listed in <Table $1>$ refers to the efficiency of tourism economics under the constraint of carbon emissions, which indicates a bad output of tourism carbon emissions, while the situation of unconstraint indicates desirable outputs only. There is a comparison between the results of constrained efficiency of tourism economics and unconstrained efficiency of tourism economics, and as it can be seen, the average values of efficiency among 27 provinces and cities during the year of 2005-2015 are listed in <Table 2>, in which SBM-UN and SBM respectively represent average value of efficiency of tourism economics under the constraint of carbon emissions and the average value of unconstrained efficiency of tourism economics.

<Table 1> Efficiency of tourism economics in 27 provinces and cities (2005-2015)

\begin{tabular}{|c|c|c|c|c|c|c|c|c|c|c|c|}
\hline Region & 2005 & 2006 & 2007 & 2008 & 2009 & 2010 & 2011 & 2012 & 2013 & 2014 & 2015 \\
\hline Beijing & 0.9623 & 0.8016 & 0.7744 & 0.7632 & 0.7784 & 0.8273 & 0.8421 & 0.8618 & 1.0000 & 0.9905 & 0.9473 \\
\hline Tianjin & 1.0000 & 1.0000 & 1.0000 & 1.0000 & 1.0000 & 1.0000 & 1.0000 & 1.0000 & 1.0000 & 1.0000 & 1.0000 \\
\hline Liaoning & 0.7160 & 0.7425 & 0.7333 & 0.7326 & 0.7801 & 0.7695 & 0.7576 & 0.7751 & 0.8433 & 0.8680 & 0.9257 \\
\hline Shanghai & 1.0000 & 1.0000 & 1.0000 & 1.0000 & 1.0000 & 1.0000 & 1.0000 & 1.0000 & 1.0000 & 1.0000 & 1.0000 \\
\hline Jiangsu & 1.0000 & 1.0000 & 1.0000 & 0.8912 & 0.9902 & 0.9271 & 0.8776 & 0.9477 & 1.0000 & 1.0000 & 1.0000 \\
\hline Zhejiang & 0.8671 & 0.9057 & 0.8802 & 0.8267 & 0.9202 & 0.9377 & 0.9676 & 1.0000 & 1.0000 & 1.0000 & 1.0000 \\
\hline Fujian & 1.0000 & 1.0000 & 1.0000 & 0.8447 & 0.9017 & 0.8877 & 0.8943 & 1.0000 & 1.0000 & 0.9100 & 0.9449 \\
\hline Shandong & 0.8414 & 0.8610 & 0.8410 & 0.7804 & 0.8639 & 0.8844 & 0.8511 & 0.7806 & 0.9591 & 0.8791 & 0.8044 \\
\hline Guangdong & 0.8578 & 0.8258 & 0.8296 & 0.7368 & 0.7279 & 0.7342 & 0.7374 & 0.7819 & 0.8506 & 0.9283 & 0.9790 \\
\hline Shanxi & 0.7436 & 0.8125 & 0.7715 & 0.7336 & 0.7375 & 0.7463 & 0.7594 & 0.7745 & 0.8311 & 0.8361 & 0.8660 \\
\hline Jilin & 0.9036 & 0.7412 & 0.7479 & 0.7330 & 0.7552 & 0.7574 & 0.7460 & 0.7719 & 0.7982 & 0.8111 & 0.8396 \\
\hline Heilongjiang & 0.7573 & 0.7616 & 0.7496 & 0.7779 & 0.8337 & 0.8278 & 0.7444 & 0.7515 & 0.7649 & 0.7789 & 0.7950 \\
\hline Anhui & 1.0000 & 1.0000 & 1.0000 & 1.0000 & 1.0000 & 1.0000 & 0.9229 & 0.9338 & 1.0000 & 0.9720 & 1.0000 \\
\hline Jiangxi & 0.9283 & 0.8999 & 0.9294 & 0.7680 & 0.8308 & 0.8105 & 0.7840 & 0.8416 & 0.8932 & 0.8704 & 0.9250 \\
\hline Hubei & 0.8056 & 0.7732 & 0.8033 & 0.7506 & 0.7637 & 0.7693 & 0.7718 & 0.8 & 0.9322 & 1.0000 & 1.0000 \\
\hline Hunan & 0.8284 & 0.7383 & 0.7313 & 0.7396 & 0.7649 & 0.7579 & 0.7479 & 0.7736 & 0.8107 & 0.8008 & 0.8369 \\
\hline Inner $\quad \mathrm{M}$ & 0.7360 & 0.7588 & 0.7575 & 0.7227 & 0.7367 & 0.7406 & 0.7578 & 0.7700 & 0.8623 & 0.8742 & 0.9483 \\
\hline Hainan & 0.7515 & 0.8065 & 0.7603 & 0.7094 & 0.7360 & 0.7812 & 0.8051 & 0.8186 & 0.7996 & 0.7649 & 0.8245 \\
\hline Chongqing & 0.8302 & 0.7408 & 0.7388 & 0.7070 & 0.7355 & 0.7352 & 0.7406 & 0.7561 & 0.7586 & 0.7810 & 0.8112 \\
\hline Sichuan & 0.8021 & 0.7838 & 0.7904 & 0.7251 & 0.7076 & 0.7117 & 0.7104 & 0.7304 & 0.8159 & 0.7630 & 0.7868 \\
\hline Guizhou & 0.7979 & 0.7410 & 0.8069 & 0.7035 & 0.7151 & 1.0000 & 1.0000 & 1.0000 & 1.0000 & 1.0000 & 1.0000 \\
\hline Yunnan & 1.0000 & 0.7222 & 0.7197 & 0.7025 & 0.7117 & 0.7186 & 0.7129 & 0.7186 & 0.7797 & 0.7662 & 0.7818 \\
\hline Shanxi' & 0.8157 & 0.7275 & 0.7322 & 0.7357 & 0.7285 & 0.7236 & 0.7188 & 0.7409 & 0.7690 & 0.7875 & 0.8527 \\
\hline Gansu & 0.7317 & 0.7577 & 0.7282 & 0.7090 & 0.7157 & 0.7043 & 0.7070 & 0.7279 & 0.7454 & 0.7505 & 0.7682 \\
\hline Qinghai & 0.7810 & 0.7295 & 0.7432 & 0.7186 & 0.7191 & 0.7150 & 0.7151 & 0.7211 & 0.7469 & 0.7532 & 0.7728 \\
\hline Ningxia & 0.7096 & 0.7146 & 0.7144 & 0.7354 & 0.7452 & 0.7651 & 0.7798 & 0.7809 & 0.7440 & 0.7383 & 0.7637 \\
\hline Xinjiang & 0.7491 & 0.7875 & 0.7598 & 0.7297 & 0.7582 & 0.7662 & 0.7616 & 0.7502 & 0.7639 & 0.7590 & 0.7512 \\
\hline
\end{tabular}


From the perspective of Input-Output, carbon emission is an important indicator of bad output which shouldn't be ignored in the evaluation of tourism economics. In the view of efficiency, the average of unconstrained efficiency of tourism economics leave tourism carbon emissions out of account and the value is 0.7234 , which is lower than the average value of efficiency under the constraint of tourism carbon emissions, the value is 0.8074 . According to $<$ Table 2>, a comprehensive view of constrained and unconstrained efficiency of tourism economics indicates that only Tianjin and Shanghai remain fully effective in both cases, in addition to Beijing, Shanxi, Zhejiang, Guangdong, average values of unconstrained efficiency of tourism economics in other provinces and cities are lower than the constrained efficiencies. In the different provinces and cities, gaps of average values between constrained and unconstrained efficiency of tourism economics are totally different, for example, gaps in Yunnan, Gansu, Qinghai and some other provinces are large, while gaps in Beijing, Anhui, Jiangsu are not obvious.

According to the comparison above, it can be find that there is a high possibility of underestimating the actual efficiency of tourism economics by leaving tourism carbon emissions out of account. The significance of estimating efficiency of tourism economics under the constraint of tourism carbon emissions is to give consideration to both economic and environmental benefits, in other words, instead of estimating efficiency without tourism carbon emissions for economic benefits only, and the latter condition will only attribute the inefficiency of tourism economics to the restriction of inefficiency caused by inputs and desirable output, in that case, the inefficiency of bad output caused by redundant carbon emissions of tourism industry will be ignored. The efficiency of tourism economics is an important index to measure the allocation of tourism resources. In that case, a rational assessment of the allocation of tourism resources will be badly affected if the underestimation of efficiency of tourism economics is not taken into consideration, which is mainly caused by the ignorance of tourism carbon emissions.

\subsection{Estimation of Inefficiency of Tourism Economics}

Inefficiency usually resulted from the interaction of redundancies of input and bad output, lacks of desirable output. According to SBM-Undesirable model, the inefficiency of tourism economics can be divided into three parts: Inefficiency caused by input, inefficiency caused by desirable output, inefficiency caused by bad output. The research mentioned above indicates that the efficiency of tourism economics will be underestimated in case of ignoring the constraint of tourism carbon emissions. Accordingly, it is necessary to evaluate the inefficiency caused by tourism carbon emissions. As it can be seen in <Table 3>, the average inefficiencies caused by tourism carbon emissions during the year of $2005-2015$ in 27 provinces and cities, which can be divided into three areas, are presented.

In <Table 3>, the average values of inefficiency caused by tourism carbon emissions during the year of 2005-2015 in 27 provinces and cities are arranged by areas of the east, the middle and the west. It can be seen that both Shanghai and Tianjin take zero as average value of inefficiency, and there is no redundancy in tourism carbon emissions. For Anhui and Jiangsu, the average values of inefficiency are less than 0.1 , and their contributions to the overall inefficiency of tourism economics account for $6.4 \%$ and $16.5 \%$ respectively, both gaps of Anhui and Jiangsu between actual tourism carbon emissions and the best production frontier are not big. On the contrary, the average values of inefficiency are greater than 0.5 in Shanxi', Ningxia, Qinghai, Gansu, which indicate obvious redundancy of tourism carbon emissions, what's more, the contributions of redundancy to the inefficiencies of tourism economics in those provinces and cities account for more than 30\%.

From the perspective of area, the average inefficiency value caused by tourism carbon emissions in the eastern area is 0.3 , In addition to Liaoning and Guangdong, the average values of inefficiency in other provinces and cities are lower than the overall average value in the east. The average value of inefficiency caused by tourism carbon emissions in the middle area is 0.37 , the levels of average inefficiency caused by tourism carbon emissions vary considerably among provinces and cities, and inefficiencies

<Table 2> Average values of constrained and unconstrained efficiency (2005-2015)

\begin{tabular}{|c|c|c|c|c|c|c|c|c|}
\hline $\begin{array}{c}\text { Provinces } \\
\text { ( Cities ) }\end{array}$ & SBM & SBM-UN & $\begin{array}{c}\text { Provinces } \\
\text { ( Cities ) }\end{array}$ & SBM & SBM-UN & $\begin{array}{c}\text { Provinces } \\
\text { ( Cities ) }\end{array}$ & SBM & SBM-UN \\
\hline Beijing & 0.8743 & 0.8681 & Zhejiang & 0.9564 & 0.9368 & Chongqing & 0.6961 & 0.7578 \\
\hline Tianjin & 1.0000 & 1.0000 & Anhui & 0.9785 & 0.9844 & Sichuan & 0.6296 & 0.7570 \\
\hline Shanxi & 0.8402 & 0.7829 & Fujian & 0.9307 & 0.9439 & Guizhou & 0.8503 & 0.8877 \\
\hline Inner Mongolia & 0.6618 & 0.7877 & Jiangxi & 0.8505 & 0.8619 & Yunnan & 0.5863 & 0.7576 \\
\hline Liaoning & 0.7485 & 0.7858 & Shandong & 0.7600 & 0.8497 & Shanxi' & 0.7064 & 0.7575 \\
\hline Jilin & 0.7023 & 0.7823 & Hubei & 0.7094 & 0.8345 & Gansu & 0.4872 & 0.7314 \\
\hline Heilongjiang & 0.7113 & 0.7766 & Hunan & 0.6379 & 0.7755 & Qinghai & 0.5400 & 0.7378 \\
\hline Shanghai & 1.0000 & 1.0000 & Guangdong & 0.9594 & 0.8172 & Ningxia & 0.7137 & 0.7446 \\
\hline Jiangsu & 0.9520 & 0.9667 & Hainan & 0.7543 & 0.7780 & Xinjiang & 0.6529 & 0.7578 \\
\hline
\end{tabular}


<Table 3> Average values of inefficiency caused by tourism carbon emissions (2005-2015)

\begin{tabular}{|c|c|c|c|c|c|c|c|c|c|}
\hline Region & IEC & Region & IEC & Region & IEC & Region & IEC & Region & IEC \\
\hline East & 0.30 & Zhejiang & 0.13 & Jilin & 0.44 & West & 0.51 & Yunnan & 0.48 \\
\hline Beijing & 0.26 & Fujian & 0.11 & Heilongjiang & 0.45 & Inner M & 0.42 & Shanxi' & 0.49 \\
\hline Tianjin & 0.00 & Shandong & 0.30 & Anhui & 0.03 & Hainan & 0.44 & Gansu & 0.54 \\
\hline Liaoning & 0.43 & Guangdong & 0.37 & Jiangxi & 0.28 & Chongqing & 0.48 & Qinghai & 0.52 \\
\hline Shanghai & 0.00 & Middle & 0.37 & Hubei & 0.33 & Sichuan & 0.49 & Ningxia & 0.51 \\
\hline Jiangsu & 0.07 & Shanxi & 0.43 & Hunan & 0.45 & Guizhou & 0.22 & Xinjiang & 0.48 \\
\hline
\end{tabular}

in Anhui, Jiangxi and Hubei are lower than the overall average value in the middle. The inefficiency caused by tourism carbon emissions in the western area is very obvious, the average value is 0.51 . In this area, tourism carbon emissions in those provinces and cities are generally ineffective, especially in Gansu, Qinghai and Ningxia. No matter the eastern area, the middle area, the western area or the provinces and cities in the three areas, the differences of inefficiencies caused by tourism carbon emissions among areas tend to be obvious, the east is remarkably superior to the middle and the west, and inefficiencies caused by tourism carbon emissions in the three areas account for $26.9 \%, 27.3 \%, 33.8 \%$ respectively to the overall inefficiency of tourism economics.

In the view of the relationship between the inefficiency caused by tourism carbon emissions and the efficiency of tourism economics under the constraint of tourism carbon emissions, it is obvious that the lower the average inefficiency caused by tourism carbon emissions, the higher the average efficiency of tourism economics, the vice versa.

\section{Discussion}

\subsection{Conclusion}

First of all, total and intensity of tourism carbon emissions in 27 provinces and cities during the year of 2005-2015 are estimated respectively with the help of tourism consumption stripping coefficient, the total of tourism carbon emissions among provinces and cities varies between 0-3000 million tons, there are obvious scale differences of tourism carbon emissions. Totals of tourism carbon emissions among the east area, the west area and the middle area are ranked in descending order, but the growth rates of the west area and the middle area are faster than the east area, and the west area stay the fastest. A further study on intensity of tourism carbon emissions indicates obvious differences among regions and areas, intensity of tourism carbon emissions in the east area, the middle area and the west area are ranked in ascending order. From 2005 to 2015, no matter from the perspective of provinces and cities or from the perspective of areas, the overall tendency of tourism carbon intensity is decreasing, which indicates a decreased dependence of tourism economic on tourism carbon emissions

Secondly, with the help of SBM-Undesirable model, a further study on the relationship between tourism carbon emissions and tourism economics, which estimate the efficiency of tourism economics in 27 provinces and cities during the year of 2005-2015, is carried out, in which the tourism carbon emission is viewed as an indicator of bad output. In the comparison between constrained efficiency of tourism economics and unconstrained efficiency, the latter is of high possibility to underestimate the former. In the case of leaving tourism carbon emissions out of account for economic benefits only, the low level of efficiency will drive the optimization of inputs and desirable outputs, and the bad output caused by tourism carbon emissions will be ignored, thereupon then, the redundancy of tourism carbon emissions will increase to lead a one-sided situation in which the tourism will develop at the expense of the environment, and may lead to unreasonable evaluation of tourism resource allocation to the brigade. It is important to find out the significance of defining the constraints of tourism carbon emissions, and the further decomposition of inefficiency of tourism economics will make it more clearly. The distribution of inefficiencies caused by tourism carbons emissions among provinces and cities is not even, in any provinces and cities, the lower the average inefficiency of tourism economics, the higher the average efficiency of tourism economics, and vice versa.

\subsection{Suggestion}

After a thorough consideration of the analysis mentioned above, several tips are proposed as below: First of all, in view of the difference of tourism carbon emissions, provinces and cities should adjust their total tourism carbon emissions and reduce their dependence on tourism carbon emissions according to their own modes and needs for tourism development. What's more, the characteristics of "carbon" in tourism activities are becoming more and more obvious, it is necessary to evaluate tourism economics under the constraint of tourism carbon emissions to take both 
economic and environmental benefits into consideration. Finally, with regard to the difference in the efficiency of tourism, provinces and cities should rationally configure the existing tourism resources, reduce the redundancy of tourism carbon emissions and improve the efficiency of tourism economics by improving the level of technical efficiency and promoting technological progress, it is also a good way to develop routes for low-carbon tourism according to the level of tourism.

\section{References}

Barros, C. P. (2006). Assessing the efficiency of travel agencies with a stochastic cost frontier: A Portuguese case study. International Journal of Tourism Research, 8(5), 367-379.

Becken, S., \& Patterson, M. (2006). Measuring national carbon dioxide emissions from tourism as a key step towards achieving sustainable tourism. Tourism Management, 31(2), 285-290.

Camelia, S., Razvan, S. M., \& Breda, Z. (2012). An input- output approach of $\mathrm{CO}_{2}$ emissions in tourism sector in post-communist Romania. Procedia Economics and Finance, 3, 987-992.

Chen, F., \& Zhu, D. (2009). Theory of research on low-carbon city: Shanghai empirical analysis. Urban Studies, 16(10), 71-79.

Choi, I. S., \& Lee, S. Y. (2012). A study on the regulatory environment of the French distribution industry and the intermarche's management strategies. International Journal of Industrial Distribution \& Business, 3(1), 7-16.

Fang, Y., Huang, Z., Yu, F., \& Tu, W. (2013). Evolution analysis of relative efficiency of provincial tourist resources. Scientia Geographica Sinica, 33(11), 1354-1361.
Gong, Y., Yang, Z., \& Tang, C. (2016). A research on the measurement and influential factors of tourism industrial efficiency in the Yangtze river economic zone. East China Economic Management, 30(9), 66-74.

Han, Y., \& Wu, P. (2016). The measurement and comparative study of carbon dioxide emissions from tourism industry: Beijing-Tianjin-Hebei. Human Geography, 31(4), 127-134.

$\mathrm{Li}$, J., \& Li, M. (1999). Study on tourism industry and the calculation of added value of tourism. Tourism Tribune, 5, 16-19.

Munday, M., Turner, K., \& Jones, C. (2013). Accounting for the carbon associated with regional tourism consumption. Tourism Management, 36(3), 35-44.

Sun, J., Zhang, J., Tang, G., Hu, H., \& Chen, M. (2016). Review on carbon emissions by tourism transportation. China Population. Resources and Environment, 26(5), 73-82.

Tao, Y., Huang, Z., Wu, L., Yu, F., \& Wang, K. ( 2014). Measuring carbon dioxide emissions for regional tourism and its factor decomposition: A case study of Jiangsu province. Acta Geographica Sinica, 69(10), 1438-1448.

Wang, K., Huang, Z., Tao, Y., \& Fang, Y. (2013). Study on spatial characteristics and spillover effects of urban tourism efficiency: A case of Yangtze River delta. Economic Geography, 33(4), 161-167.

Zhao, J. (2016). The change differences and influence mechanism of TFP in China's tourism industry under the environmental constraint. Journal of Shanxi University of Finance and Economics, 38(10), 61-74.

Zha, J. (2016). Study on energy consumption, carbon dioxide emission and low-carbon efficiency. China Population, Resources and Environment, 26(1), 47-54. 